\title{
Surgical treatment of joint burn scar contracture: a 10-year single- center experience with long-term outcome evaluation
}

\author{
Zhouji Ma ${ }^{1 \#}$, Ran Mo ${ }^{1,2 \#}$, Chen Chen ${ }^{3 \#}$, Xueyong Meng ${ }^{2}$, Qian Tan ${ }^{1,2}$ \\ ${ }^{1}$ Department of Burns \& Plastic Surgery, Nanjing Drum Tower Hospital Clinical College of Nanjing Medical University, Nanjing, China; \\ ${ }^{2}$ Department of Burns \& Plastic Surgery, Nanjing Drum Tower Hospital, the Affiliated Hospital of Medical School of Nanjing University, Nanjing, \\ China; ${ }^{3}$ Department of Nutrition, Nanjing Drum Tower Hospital, the Affiliated Hospital of Medical School of Nanjing University, Nanjing, China \\ Contributions: (I) Conception and design: R Mo; (II) Administrative support: Q Tan; (III) Provision of study materials or patients: R Mo, Z Ma; (IV) \\ Collection and assembly of data: R Mo, Z Ma, C Chen; (V) Data analysis and interpretation: R Mo, Z Ma, C Chen; (VI) Manuscript writing: All \\ authors; (VII) Final approval of manuscript: All authors. \\ \#These authors contributed equally to this work. \\ Correspondence to: Qian Tan. Department of Burns \& Plastic Surgery, Nanjing Drum Tower Hospital Clinical College of Nanjing Medical University; \\ Department of Burns \& Plastic Surgery, Nanjing Drum Tower Hospital, the Affiliated Hospital of Medical School of Nanjing University, 321 \\ Zhongshan Road, Nanjing 210008, China. Email: smmutanqian@sina.com.
}

Background: Burn patients often have functional problems due to joint scar contracture. Patients suffering from such contracture often experience considerable limitations in daily life. Therefore, surgical treatment is often necessary. Skin grafts, especially full-thickness skin grafts and flaps remain the most commonly used surgical methods in clinical practice. However, there are no clear guidelines stating which technique is the most effective treatment. Herein, we conducted a retrospective cohort study over 10 years of experience at a single center to investigate whether flaps or FTSGs exhibit a better long-term effect.

Methods: We performed a retrospective chart review of patients with joint burn scar contracture and collected data related to patient demographic profiles, and detailed descriptions of the scars, surgical procedures, and follow-up were collected. We performed follow-up evaluation of three aspects: adverse events (recontracture, ache, and pruritus), satisfaction scores for function and aesthetics, and scar quality (Vancouver Scar Scale score).

Results: Follow-up results 1 year after surgery from 88 patients were analyzed. In total, 4 (10\%) patients in the flap group and 13 (27.1\%) patients in the FTSG group had recontracture; the incidence of recontracture was lower in the flap group than in the FTSG group $(\mathrm{P}=0.043)$. The functional satisfaction score of the flap group was higher than that of the FTSG group $(\mathrm{P}=0.027)$. Moreover, follow-up results 5 year after surgery for 47 patients were analyzed. In total, 1 (4.8\%) patient in the flap group and $7(26.9 \%)$ patients in the FTSG group had recontracture; the incidence of recontracture was significantly lower in the flap group than in the FTSG group $(\mathrm{P}=0.044)$. The functional satisfaction score in the flap group was higher than that of the FTSG group $(\mathrm{P}=0.041)$. In this study, no significant differences in scar quality were observed between the two groups.

Conclusions: If conditions permit, the application of different types of flaps may represent a better choice than FTSGs in terms of reducing the recontracture rate and improving joint function.

Keywords: Scar contracture; joint; surgical flaps; skin grafting

Submitted Jun 25, 2020. Accepted for publication Nov 15, 2020.

doi: 10.21037/atm-20-4947

View this article at: http://dx.doi.org/10.21037/atm-20-4947 


\section{Introduction}

Burn patients often have functional problems due to scar contracture, as contracture causes the scar tissue to have a reduced or unstable range of motion. Joint burn scar contracture is defined as a process in which normal skin is replaced by pathological scar tissue with insufficient length and elongation capacity, resulting in a reduction in the range of motion or misalignment of the anatomical structures or tissue of the joints involved (1). The incidence of burn scar contracture is between $18 \%$ and $50 \%$ (2-5). Functional limitations may affect patients' ability to work and may even affect their daily activities, including opening jars, dressing, and opening doors. In the most serious cases, patients may lose the ability to live independently, which causes severe economic and emotional damage to individuals, families, and society (6).

To address existing joint burn scar contracture, dermatologists may employ light- and laser-based therapies (ablative fractional laser, nonablative fractional laser, pulsed dye laser, etc.), and patients can achieve a certain degree of joint movement and aesthetic improvement $(7,8)$. However, for scar contracture that markedly limits joint movement, reconstruction surgery is often a direct and effective treatment (9). Transplantation of skin grafts after the release or excision of scar contractures, especially fullthickness skin grafts (FTSGs), has always been a common method (10). Various types of flaps have also been used clinically to address defects in different situations. In addition, new techniques have emerged, such as dermal substitutes (11) and lipofilling (12). Skin grafts and flaps are still the most commonly used surgical methods in clinical practice. However, a recent systematic review revealed that it is unclear which surgical technique is the most effective to resolve joint burn scar contracture (13). Although a randomized controlled trial of perforator flaps in the treatment of burn scar contracture was performed (14), the number of cases was insufficient. That study is the only randomized controlled experiment to date; thus, one cannot draw conclusions supported by strong evidence to guide clinical practice. Therefore, we conducted a retrospective cohort study of 10 years of experience in a single center to investigate whether flaps or FTSGs have better long-term effects.

We present the following article in accordance with the Strengthening the Reporting of Observational Studies in Epidemiology (STROBE) reporting checklist (available at http://dx.doi.org/10.21037/atm-20-4947).

\section{Methods}

\section{Patients}

We retrospectively analyzed patients with joint burn scar contracture, enrolling those who were treated with flaps or FTSGs $(\mathrm{N}=130)$. The exclusion criteria were as follows (Figure 1). First, we excluded patients who underwent surgery with a combination of flaps and FTSG technology $(\mathrm{N}=6)$ because these cases were beyond the scope of this study. Second, we excluded patients with multiple scar contractures $(\mathrm{N}=5)$ to facilitate comparisons between the baseline characteristics of the two groups, and because we included functional and aesthetic satisfaction scores in the followup evaluation parameters to control for the interference or bias of different surgical effects on different joints of the same patient. Third, we excluded patients with secondary joint ankylosis $(\mathrm{N}=5)$ because it was important to distinguish between joint ankylosis and joint scar contracture. Ankylosis involves deeper tissues, including bone, cartilage, and joint capsules, which cannot be resolved simply by the release and excision of the scar. Ankylosis can typically be distinguished from simple scar contracture by radiography. In addition, because some patients were lost to follow-up ( $N=26)$, the clinical and follow-up data of only 88 patients were ultimately included in the analysis. Patient data were collected from medical records from 2010 to 2019 at Nanjing Drum Tower Hospital, China. The current study was approved by the ethics committee of Nanjing Drum Tower Hospital Clinical College of Nanjing Medical University, the Affiliated Hospital of Nanjing University Medical School (2020-10901). Written informed consent was obtained from the patient for publication of this study and any accompanying images. The study was conducted in accordance with the Declaration of Helsinki (as revised in 2013).

The patients' baseline demographic and clinical characteristics are displayed in Table 1, including gender, age, smoking, diabetes, hypertension, scar localization, etiology, symptoms, duration, surface area and defect size after release, are displayed in Table 1. There was no statistically significant difference in baseline demographics between the two groups. All operations were performed by three senior doctors.

All patients received early postoperative rehabilitation treatment during their hospitalization.

\section{Surgical technique}

A total of 88 patients with joint burn scar contracture were 


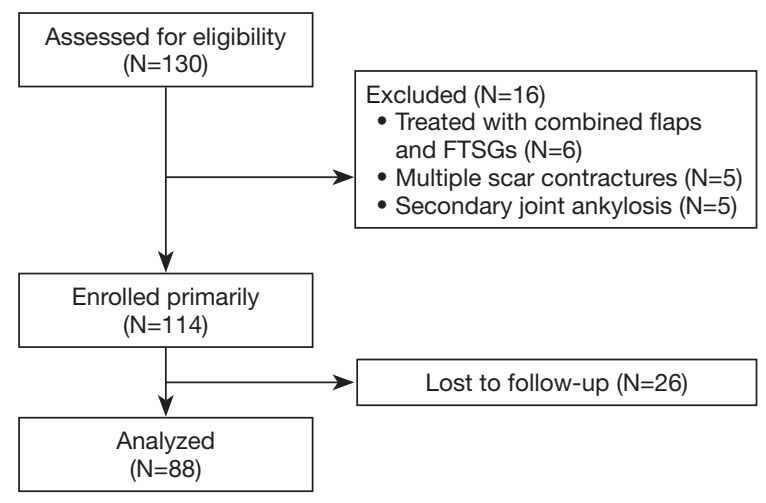

Figure 1 Flowchart of enrollment. FTSGs, full-thickness skin grafts. included in this study (Table 1). In total, 26 (29.5\%) cases involved the neck, 15 (17.0\%) cases involved the shoulders, $20(22.7 \%)$ cases involved the large joints of the limbs (elbows, wrists, knees, and ankles), and 27 (30.7\%) cases involved the small joints of the limbs (metacarpophalangeal joints, interphalangeal joints, and metatarsophalangeal joints). Among the 88 patients, 40 underwent flap surgery. According to the different locations and defects, different types of flaps were applied (Table 2), including local flaps $(\mathrm{N}=24,27.3 \%)$, expanded flaps $(\mathrm{N}=10,11.4 \%)$, distal abdominal pedicle flaps $(\mathrm{N}=4,4.5 \%)$, latissimus dorsi flaps $(\mathrm{N}=1,1.1 \%)$ and gastrocnemius flaps $(\mathrm{N}=1,1.1 \%)$. In total,48 patients underwent FTSGs surgery. All

Table 1 Baseline demographic and clinical characteristics of both treatment groups

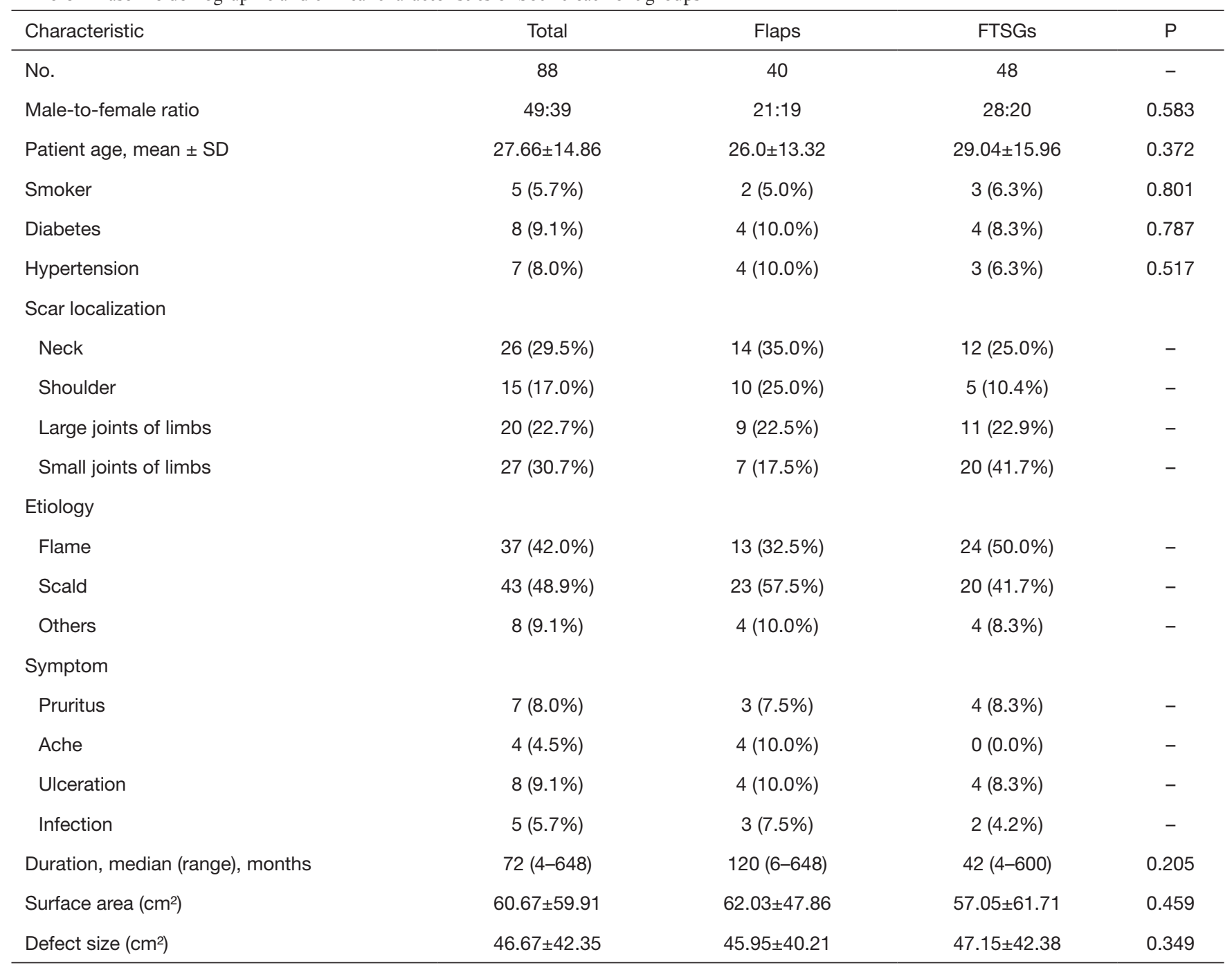

Large joints of limbs: elbows, wrists, knees, and ankles; small joints of limbs: metacarpophalangeal joints, interphalangeal joints, and metatarsophalangeal joints; others: electricity, chemicals, and hot crush injury. FTSGs, full-thickness skin grafts. 
Table 2 Operation characteristics

\begin{tabular}{lcc}
\hline & N & Range or \% \\
\hline Flaps & 40 & 45.5 \\
Type & 24 & 27.3 \\
Local flap & 10 & 11.4 \\
Expanded flap & 4 & 4.5 \\
Distant abdominal pedicle flap & 1 & 1.1 \\
Latissimus dorsi flap & 1 & 1.1 \\
Gastrocnemius flap & 12 & $2-50$ \\
Mean hospital stay (days) & 132 & $64-237$ \\
Mean operation time (min) & 48 & 54.5 \\
FTSGs & & \\
Harvest region & 25 & 28.4 \\
Abdomen & 13 & 14.8 \\
Thigh & 10 & 11.4 \\
Arm & 13 & $9-31$ \\
Mean hospital stay (days) & 131 & $40-285$ \\
Mean operation time (min) & & \\
\hline
\end{tabular}

FTSGs, full-thickness skin grafts.

patients underwent rehabilitation training by professional rehabilitation physicians during their postoperative hospitalization.

\section{Flaps}

Scar contractures should be completely released or excised. In many cases, we can choose local flaps, such as Z-plasty, continuous Z-plasty, and five-flap plasty (combined Z-plasty and $\mathrm{Y}-\mathrm{V}$ advancement flap), to resurface the defect. During the operation, we designed an incision line along which we cut the skin and the subcutaneous tissue down to the deep fascia layer, and then we freely formed each flap along the shallow surface of the deep fascia. After assessing for normal blood flow, we interlaced or advanced the flap. If necessary, the subcutaneous tissue and skin was sutured in two layers, and drainage was used. We could also choose to apply an expanded flap. This method involves expanding skin and soft tissues by using skin and soft tissue expanders and increasing the amount of these tissues available to repair skin and soft tissue defects on various parts of the body surface. Typically, in the first stage of surgery, a tissue expander is implanted under the normal skin around the scar and injected with normal saline twice a week, typically for 12 weeks. The clinician decided the timing of the second operation by determining how much expanded area would be needed. In the second stage of surgery, local expansion flaps were designed, and the defect was covered by advancement, rotation or translocation of flaps during the operation. Tissue defects of the hands and wrists could be repaired with distal abdominal pedicle flaps and pedicled with blood vessels such as the superficial circumflex iliac artery or the superficial inferior epigastric artery. After the flap was placed over the defect, it was sutured intermittently, and the dressing was used to maintain the upper limbs and abdomen in a fixed position with tapes, abdominal bands, etc. After the defect was covered using a one-stage surgery, the pedicle was cut off in time according to the patient's flap survival status. Three weeks after surgery, the patient's flap pedicle was clamped with covered hemostatic forceps to examine the flap survival status. In addition, we applied a latissimus dorsi flap to release burn scar contracture of the shoulder in 1 case, and we used a gastrocnemius flap to release burn scar contracture of the knee in 1 case. The donor site of the flap was closed with primary sutures. The average hospital stay in the flap group was 12 days (2-50 days), and the average operation time was 132 minutes (64-237 minutes).

\section{FTSGs}

After the scar contracture was released and excised, the area of the skin defect was measured intraoperatively. The area of the donor FTSGs was slightly smaller than the area of the defects. Different parts of the nonscar area were chosen as the donor areas for FTSGs, including the abdomen $(\mathrm{N}=25)$, thigh $(\mathrm{N}=13)$, and arm $(\mathrm{N}=10)$. Surgeons cut the skin along predesigned lines as deep as the superficial fascia layer and isolated skin grafts with subcutaneous fat, which were removed completely from the donor site. Bleeding was carefully stopped at the base of the donor site carefully, and sutures were applied in situ. The skin grafts were trimmed of excess fat and made into FTSGs. The free FTSGs were used to cover the distant defects, and they were wrapped and compressed after intermittent suture. The surgical site was immobilized locally after surgery, and a splint or plaster was applied if necessary. Patients in the FTSG group had an average hospital stay of 13 days (9-31 days) and an average surgery time of 131 minutes (40-285 minutes). 
Table 3 Follow-up results at 1 year after surgery

\begin{tabular}{lccc}
\hline & Flaps $(\mathrm{N}=40)$ & FTSGs $(\mathrm{N}=48)$ & $\mathrm{P}$ \\
\hline Adverse event & & & \\
Recontracture & $4(10.0 \%)$ & $13(27.1 \%)$ & $0.043^{\star}$ \\
Ache & $1(2.5 \%)$ & $4(8.3 \%)$ & 0.475 \\
Pruritus & $15(37.5 \%)$ & $23(47.9 \%)$ & 0.326 \\
Satisfaction score & & & \\
Function & $4.38 \pm 0.71$ & $3.88 \pm 1.16$ & $0.027^{\star}$ \\
Aesthetics & $3.45 \pm 0.99$ & $3.29 \pm 1.03$ & 0.610 \\
Scar quality & & & \\
Total VSS score & $5.77 \pm 1.74$ & $6.55 \pm 1.57$ & 0.183 \\
Pigmentation & $1.60 \pm 0.81$ & $1.69 \pm 0.88$ & 0.429 \\
Vascularity & $1.33 \pm 0.63$ & $1.42 \pm 0.61$ & 0.679 \\
Pliability & $1.80 \pm 0.61$ & $1.92 \pm 0.77$ & 0.538 \\
Height & $0.95 \pm 0.60$ & $1.08 \pm 0.90$ & 0.663 \\
\hline
\end{tabular}

${ }^{*} \mathrm{P}<0.05$. FTSGs, full-thickness skin grafts; VSS, Vancouver Scar Scale.

\section{Follow-up}

Follow-up was performed by telephone, outpatient clinic visits, or online communication software. Patients were followed up every three months after discharge from the hospital, and the total follow-up duration was greater than 1 year. Because the purpose of this study was to evaluate the long-term effects, the data at the 1-year follow-up were included in the analysis. In addition, data from patients who were followed for more than five years were also included in the analysis.

\section{Outcome evaluation}

\section{Adverse events}

Adverse events included recontracture, ache, and pruritus. In our study, recontracture was defined by a bundle-like scar observed and a reduced range of motion compared with discharge, with partial or total recurrence of the preoperative problem. The numbers of people with ache and pruritus after one year were recorded in both groups.

\section{Functional and aesthetic satisfaction scores}

During follow-up, each patient scored functional and aesthetic improvements compared to the preoperative period. The rating scale ranged from 1 to 6 , where $1=$ completely dissatisfied and $6=$ completely satisfied.

\section{Scar quality}

The Vancouver Scar Scale is a widely used tool for evaluating scar quality. This scale is a clinical evaluation of four variables, namely, "vascularization" $(0$ points $=$ normal color, 1 point $=$ pink, 2 points $=$ dark red, or 3 points $=$ purple), "height" ( 0 points $=$ flat, 1 point $=$ less than $2 \mathrm{~mm}$, 2 points $=2-5 \mathrm{~mm}, 3$ points $=$ greater than $5 \mathrm{~mm})$, "flexibility" ( $0=$ normal, $1=$ soft, $2=$ yielding, $3=$ hard, $4=$ ropelike, or $5=$ contracture $)$ and "pigmentation" ( $0=$ normal, $1=$ hypopigmentation, $2=$ mixed, $3=$ hyperpigmented). The height of the scar was measured with a simple measuring stick, and the flexibility of the scar is evaluated by creating skin folds. Each variable had four to six levels, as specified above. Total possible scores ranged from 0 to 14 , with a score of 0 indicating normal skin.

\section{Statistical analysis}

Statistical analysis and graphing were performed using IBM SPSS version 26.0 (SPSS, Chicago, IL, USA, RRID:SCR_002865) and GraphPad version 8.0 (GraphPad Software, San Diego, CA, USA, RRID:SCR_002798). The normality of the distribution was tested by calculating skewness and kurtosis, evaluating a frequency histogram, and performing the Shapiro-Wilk test. An independent $t$-test (in the case of a normal distribution) or MannWhitney $\mathrm{U}$ test (in the case of a nonnormal distribution) was used to test for significant differences between data from independent groups. To assess differences in nonlevel count data, a chi-square test was used. The two-tailed significance threshold was set at 0.05 .

\section{Results}

The follow-up results at 1 year after surgery are shown in Table 3. In terms of long-term adverse events, $4(10.0 \%)$ patients in the flap group and $13(27.1 \%)$ patients in the FTSG group exhibited recontracture; the incidence of recontracture was significantly lower in the flap group than in the FTSG group. A significant difference between was noted the two groups $(\mathrm{P}=0.043$, Figure 2$)$. One $(2.5 \%)$ patient in the flap group and 4 patients $(8.3 \%)$ in the FTSG group experienced pain symptoms, but the incidence of this symptom was not significantly different between the two groups $(\mathrm{P}=0.475)$. There were $15(37.5 \%)$ cases of pruritus in the flap group and $23(47.9 \%)$ cases in the full-thickness 

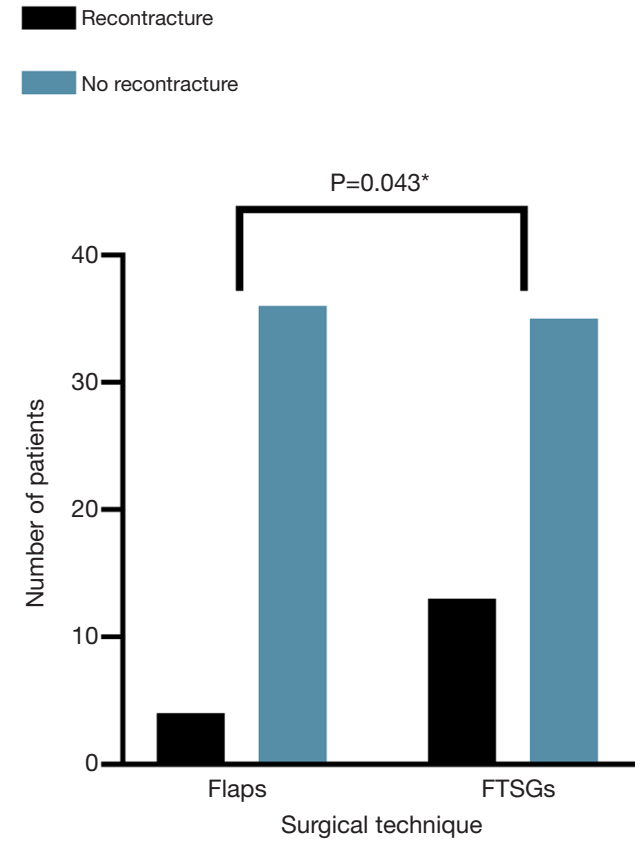

Figure 2 Recontracture of both groups. ${ }^{*} \mathrm{P}<0.05$. FTSGs, fullthickness skin grafts.

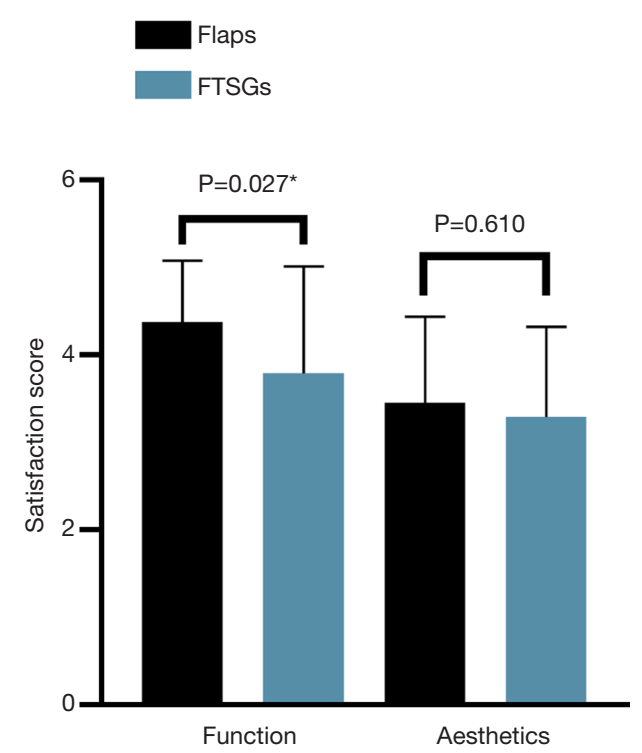

Figure 3 Satisfaction score for function and aesthetics of both groups. ${ }^{*} \mathrm{P}<0.05$. FTSGs, full-thickness skin grafts.

skin group, however, no significant difference was noted between the two groups $(\mathrm{P}=0.326)$.

The functional satisfaction score of the flap group was $4.38 \pm 0.71$, and the aesthetic satisfaction score of the FTSG

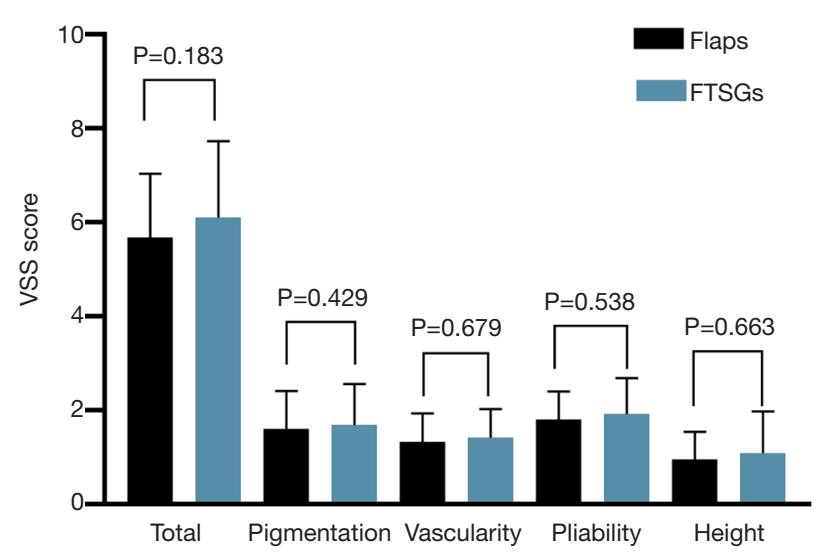

Figure 4 VSS score of both groups. FTSGs, full-thickness skin grafts; VSS, Vancouver Scar Scale.

group was $3.88 \pm 1.16$. The functional satisfaction score of the function of the flap group was higher than that of the FTSG group ( $\mathrm{P}=0.027$, Figure 3$)$. The aesthetic satisfaction score of the flap group $(3.45 \pm 0.99)$ was higher than that of the FTSG group (3.29 \pm 1.03$)$. However, no significant difference was noted between the two groups $(\mathrm{P}=0.610)$.

In addition, in the evaluation of scar quality, the flap group $(5.77 \pm 1.74)$ scored better than the FTSG group $(6.55 \pm 1.57)$ on the Vancouver Scar Scale, but there was no significant difference between the two $(\mathrm{P}=0.183$, Figure 4). The flap group $(1.60 \pm 0.81)$ scored better than the FTSGs $(1.69 \pm 0.88)$ in pigmentation, but no significant difference was noted between the two groups $(\mathrm{P}=0.429)$. The flap group $(1.33 \pm 0.63)$ scored better than the FTSG group $(1.42 \pm 0.61)$ in vascularization, but there was no significant difference between the two groups $(\mathrm{P}=0.679)$. The flap group $(1.80 \pm 0.61)$ scored better than the FTSG group $(1.92 \pm 0.77)$ in flexibility, but there was no significant difference between the two groups. Finally, the flap group $(0.95 \pm 0.60)$ scored better than the FTSG group $(1.08 \pm 0.90)$ in height, but no significant difference was noted between the two groups.

Moreover, in the analysis of data from patients who had been followed for more than five years $(\mathrm{N}=47)$, 21 underwent flap surgery and 26 underwent FTSG surgery. No statistically significant difference in baseline demographics two groups including gender, age, smoking, diabetes, hypertension, duration, surface area and defect size, were noted between the two groups. The followup results at 5 years after surgery are shown in Table S1. In total, 1 (4.8\%) patient in the flap group and 7 (26.9\%) patients in the FTSG group experienced recontracture; the 

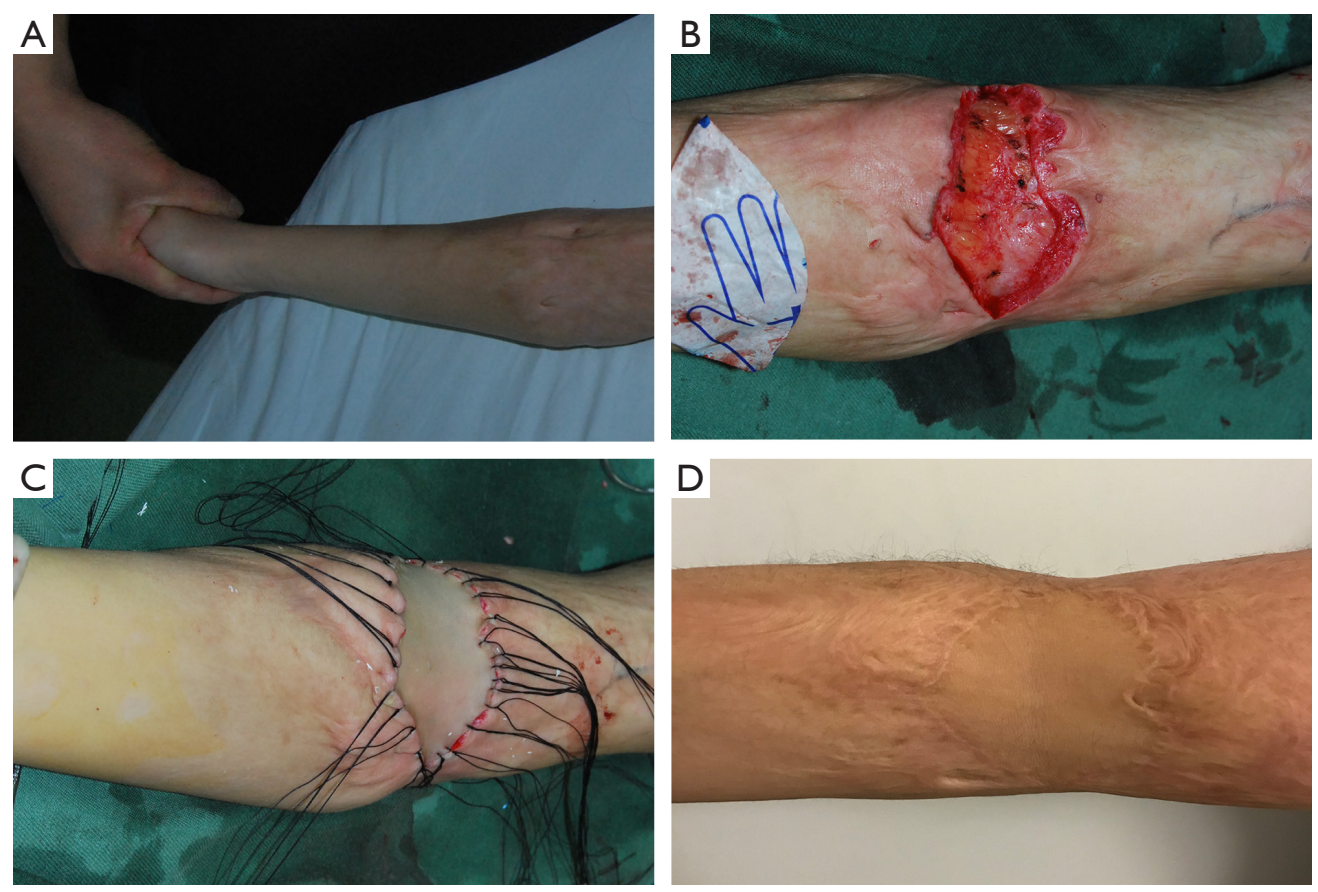

Figure 5 Long-term outcome of FTSGs. Appearance of pre-, peri-, and postoperation. (A) Appearance of preoperation; (B) scar release and excision; (C) defect covered with FTSGs; (D) appearance 1 year later. FTSGs, full-thickness skin grafts.

incidence of recontracture was significantly lower in the flap group than in the FTSG group $(\mathrm{P}=0.044)$. The functional satisfaction score of the flap group was higher than that of the FTSG group $(\mathrm{P}=0.041)$. No significant difference in incidence of ache $(\mathrm{P}=0.495)$, pruritus $(\mathrm{P}=0.218)$, aesthetic satisfaction score $(\mathrm{P}=0.893)$ and scar quality were noted.

\section{Case report}

A 5-year-old boy's elbow scar contracture prevented him from fully extending his elbow joint on his own. He was burned when he was 2 years old. We released and excised the scar and obtained a full-thickness skin flap from the right lower abdomen to cover the defect. The follow-up results 1 year later showed that the function and appearance improved considerably (Figure 5). Both the patient and the parent expressed satisfaction, and both function and aesthetics scored 5 points.

A 23-year-old woman's elbow scar contracture prevented her elbow joint from being fully straightened. She had been burned at 20 years of age. We implanted two kidney-shaped tissue expanders under the skin. Three months later, after complete release and excision of the scar contracture, the expanded flap covered the defect. The follow-up results after 1 year showed that the function was improved greatly and that the appearance was moderately improved (Figure 6). The patient's functional satisfaction score was 5 points, and her aesthetic satisfaction score was 4 points.

\section{Discussion}

Burn treatment technology has made great progress, but the incidence of scars caused by burns has not decreased. In developed countries, approximately 4 million burn scars every year (15). Burns at joints often form scar contractures, leading to a certain degree of functional limitations and aesthetic defects in patients. Appropriate wound care, early escharectomy, skin grafting, and early physical rehabilitation intervention can theoretically reduce the occurrence of joint burn scar contracture (16). However, a study demonstrated that even with early joint extension rehabilitation, scar contracture cannot be completely avoided (17). In addition, studies have established a mathematical model of wound healing. Once a certain threshold is exceeded, early active physical rehabilitation cannot reverse the formation of scar contractures (18) and has a negative impact on the physiological, aesthetic, psychological, and social aspects of the patient.

Release and excision of the scar followed by the placement of skin grafts to cover the defect is the classic 

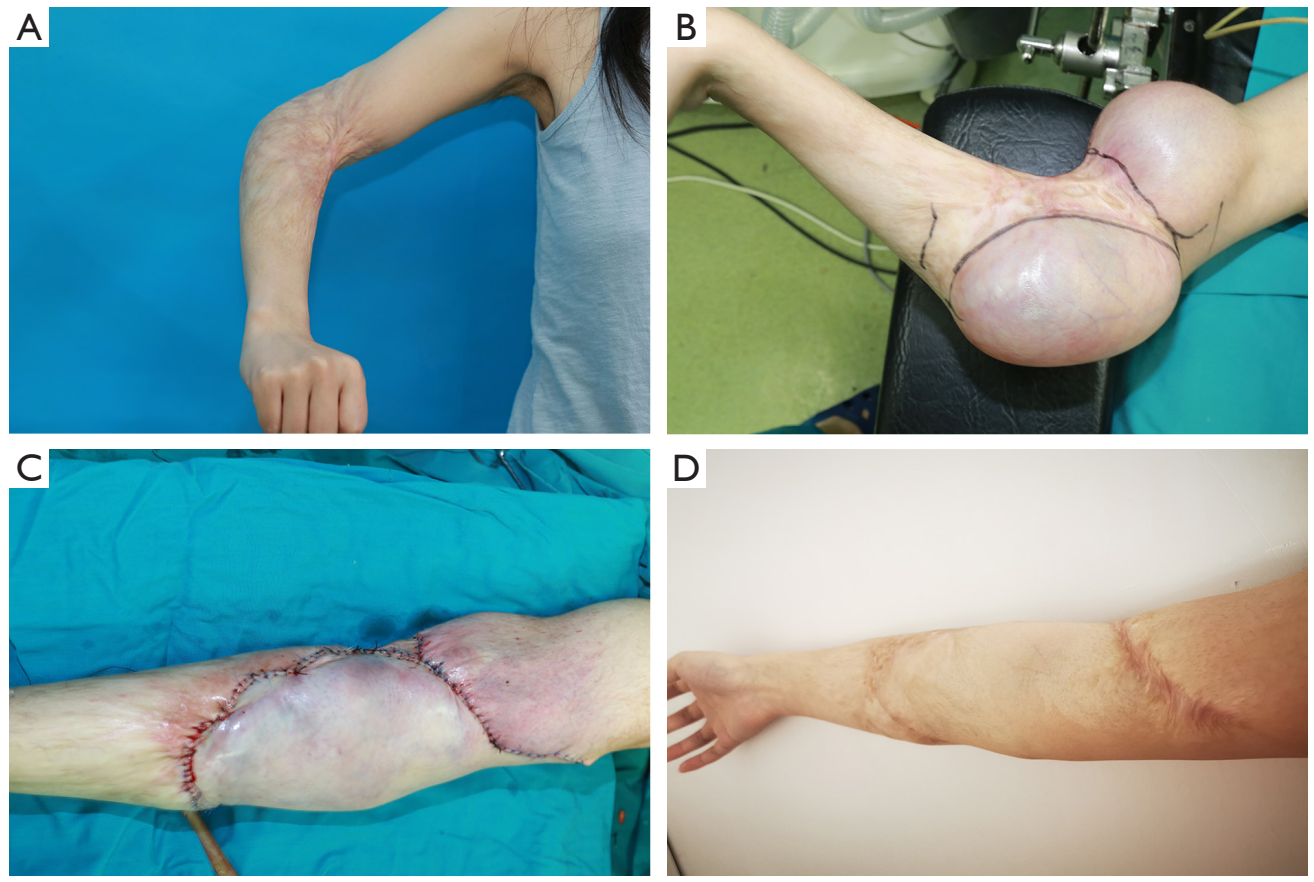

Figure 6 Long-term outcome of flaps. Appearance of pre-, peri-, and postoperation. (A) Appearance of preoperation; (B) tissue expander under the skin; (C) defect covered with an expanded flap; (D) appearance 1 year later.

surgical method for joint burn scar contracture, and it the procedure has been widely used in clinical practice. Most doctors may choose split skin grafts or full-thickness skin grafts. However, studies have confirmed that FTSGs are less prone to recontracture than split skin grafts, so FTSGs are more popular with clinicians (10). Theoretically, the thicker the skin grafts, the stronger the anti-contractive ability. In addition, flap technology has also been widely used. In the case of joint burn scar contracture within a certain width, local flaps, including $\mathrm{Z}$ flaps and their derived technologies and $\mathrm{Y}-\mathrm{V}$ advancement flaps, represent good choices. Scar contracture of upper extremity joints can be treated with free tissue transfer or with distal flaps, such as abdominal and groin flaps. Afterward, the joint must be fixed in place, and a splint is necessary to maintain mobility (19). In recent years, methods of perforator flaps have been proposed, but additional high-quality research is needed to provide more evidence. With the exception of a previously reported randomized controlled trial (14), most other studies involved preoperative and postoperative comparisons, that lack a control group $(20,21)$. In our study, the FTSG group acts as a control, which has a certain reference value.

Some studies used more objective indicators, such as the range of motion of joints (22). We did not use the range of motion because this variable is also affected and confounded by factors such as joint stiffness and contracture in other directions. Because the range of motion was measured at different positions in this study, with different ranges (for example, elbows and shoulders), we did not perform paired analysis of specific joints in this study. Therefore, we chose to use patient satisfaction as an indicator of the evaluation function and attach importance to the subjective feelings of patients.

Burn reconstruction surgery remains a major challenge. In our study, 17 (19.3\%) patients had varying degrees of contracture recurrence. Four $(10.0 \%)$ patients in the flap group had significantly lower recontracture rates than $13(27.1 \%)$ patients in the FTSG group 1 year after surgery. The difference in recontracture rates between the two interventions can be explained by the following assumptions. After the release of burn scar contracture, the wound bed formed tends to contract again due to the contraction characteristics of the scar tissue (23), and the interposed tissue (FTSGs or flaps) is affected by this contraction process. In contrast to full-thickness skin grafts, the flap contains subcutaneous fat tissue. It can be assumed that the subcutaneous fat acts as a functional sliding layer to prevent the flap from adhering to the underlying wound 
bed, making it less likely to contract again. The presence of subcutaneous fat on the flap can prevent recontracture. This notion is consistent with Grishkevich's reconstruction strategy theory (24).

This study has some limitations. First, the insufficient sample size prevents us from analyzing each subgroup of joints. Second, we did not include rehabilitation training after discharge from the hospital. Rehabilitation training is important for improving joint activity. However, because patients' compliance was inconsistent, we could not quantify it. Therefore, additional high-quality randomized controlled trials are needed to obtain further evidence.

\section{Conclusions}

If conditions permit, the application of different types of flaps may be a better choice than FTSGs in terms of reducing the recontracture rate and improving joint function.

\section{Acknowledgments}

Funding: This work was supported by the National Natural Science Foundation of China (81800241), Postgraduate Research\&Practice Innovation Program of Jiangsu Province (SJCX20_0484) and the Fundamental Research Funds for the Central Universities (14380479).

\section{Footnote}

Reporting Checklist: The authors have completed the STROBE reporting checklist. Available at http://dx.doi. org/10.21037/atm-20-4947

Data Sharing Statement: Available at http://dx.doi. org/10.21037/atm-20-4947

Conflicts of Interest: All authors have completed the ICMJE uniform disclosure form (available at http://dx.doi. org/10.21037/atm-20-4947). Dr. RM serves as an unpaid Section Editor of Annals of Translational Medicine from Jan 2020 to Dec 2020. The other authors have no conflicts of interest to declare.

Ethical Statement: The authors are accountable for all aspects of the work in ensuring that questions related to the accuracy or integrity of any part of the work are appropriately investigated and resolved. The current study was approved by the ethics committee of Nanjing Drum Tower Hospital Clinical College of Nanjing Medical University, the Affiliated Hospital of Nanjing University Medical School (2020-109-01). Written informed consent was obtained from the patient for publication of this study and any accompanying images. The study was conducted in accordance with the Declaration of Helsinki (as revised in 2013).

Open Access Statement: This is an Open Access article distributed in accordance with the Creative Commons Attribution-NonCommercial-NoDerivs 4.0 International License (CC BY-NC-ND 4.0), which permits the noncommercial replication and distribution of the article with the strict proviso that no changes or edits are made and the original work is properly cited (including links to both the formal publication through the relevant DOI and the license). See: https://creativecommons.org/licenses/by-nc-nd/4.0/.

\section{References}

1. Richard R, Baryza MJ, Carr JA, et al. Burn rehabilitation and research: proceedings of a consensus summit. J Burn Care Res 2009;30:543-73.

2. Sheffield CG, 3rd, Irons GB, Mucha P, Jr., et al. Physical and psychological outcome after burns. J Burn Care Rehabil 1988;9:172-7.

3. Leblebici B, Adam M, Bağiş S, et al. Quality of life after burn injury: the impact of joint contracture. J Burn Care Res 2006;27:864-8.

4. Schneider JC, Holavanahalli R, Helm P, et al. Contractures in burn injury: defining the problem. J Burn Care Res 2006;27:508-14.

5. Goverman J, Mathews K, Goldstein R, et al. Adult Contractures in Burn Injury: A Burn Model System National Database Study. J Burn Care Res 2017;38:e328-36.

6. Schouten HJ, Nieuwenhuis MK, van Baar ME, et al. The prevalence and development of burn scar contractures: A prospective multicenter cohort study. Burns 2019;45:783-90.

7. Hultman CS, Edkins RE, Lee CN, et al. Shine on: Review of Laser- and Light-Based Therapies for the Treatment of Burn Scars. Dermatol Res Pract 2012;2012:243651.

8. Willows BM, Ilyas $M$, Sharma A. Laser in the management of burn scars. Burns 2017;43:1379-89.

9. Hop MJ, Langenberg LC, Hiddingh J, et al. Reconstructive surgery after burns: a 10-year follow-up study. Burns 2014;40:1544-51. 
10. Iwuagwu FC, Wilson D, Bailie F. The use of skin grafts in postburn contracture release: a 10-year review. Plast Reconstr Surg 1999;103:1198-204.

11. Clayman MA, Clayman SM, Mozingo DW. The use of collagen-glycosaminoglycan copolymer (Integra) for the repair of hypertrophic scars and keloids. J Burn Care Res 2006;27:404-9.

12. Brongo S, Nicoletti GF, La Padula S, et al. Use of lipofilling for the treatment of severe burn outcomes. Plast Reconstr Surg 2012;130:374e-6e.

13. Stekelenburg CM, Marck RE, Tuinebreijer WE, et al. A systematic review on burn scar contracture treatment: searching for evidence. J Burn Care Res 2015;36:e153-61.

14. Stekelenburg CM, Jaspers ME, Jongen SJ, et al. Perforator-Based Interposition Flaps Perform Better Than Full-Thickness Grafts for the Release of Burn Scar Contractures: A Multicenter Randomized Controlled Trial. Plast Reconstr Surg 2017;139:501e-9e.

15. Bayat A, McGrouther DA, Ferguson MW. Skin scarring. Bmj 2003;326:88-92.

16. Dewey WS, Richard RL, Parry IS. Positioning, splinting, and contracture management. Phys Med Rehabil Clin N Am 2011;22:229-47, v.

17. Godleski M, Oeffling A, Bruflat AK, et al. Treating burn-associated joint contracture: results of an inpatient

Cite this article as: Ma Z, Mo R, Chen C, Meng X, Tan Q. Surgical treatment of joint burn scar contracture: a 10 -year single-center experience with long-term outcome evaluation. Ann Transl Med 2021;9(4):303. doi: 10.21037/atm-20-4947 rehabilitation stretching protocol. J Burn Care Res 2013;34:420-6.

18. Murphy KE, McCue SW, McElwain DL. Clinical strategies for the alleviation of contractures from a predictive mathematical model of dermal repair. Wound Repair Regen 2012;20:194-202.

19. Orgill DP, Ogawa R. Current methods of burn reconstruction. Plast Reconstr Surg 2013;131:827e-36e.

20. Verhaegen PD, Stekelenburg CM, van Trier AJ, et al. Perforator-based interposition flaps for sustainable scar contracture release: a versatile, practical, and safe technique. Plast Reconstr Surg 2011;127:1524-32.

21. Wang AW, Zhang WF, Liang F, et al. Pre-expanded thoracodorsal artery perforator-based flaps for repair of severe scarring in cervicofacial regions. J Reconstr Microsurg 2014;30:539-46.

22. Li H, Zhou Y, Du Z, et al. Strategies for customized neck reconstruction based on the pre-expanded superficial cervical artery flap. J Plast Reconstr Aesthet Surg 2015;68:1064-71.

23. Kwan PO, Tredget EE. Biological Principles of Scar and Contracture. Hand Clin 2017;33:277-92.

24. Grishkevich VM. Burned perineum reconstruction: a new approach. J Burn Care Res 2009;30:620-4. 
Supplementary

Table S1 Follow-up results at 5 year after surgery

\begin{tabular}{llll}
\hline & Flaps $(\mathrm{N}=21)$ & FTSGs $(\mathrm{N}=26)$ & $\mathrm{P}$ \\
\hline Adverse event & $1(4.8 \%)$ & $7(26.9 \%)$ & $0.044^{*}$ \\
Recontracture & $0(0.0 \%)$ & $2(7.7 \%)$ & 0.495 \\
Ache & $6(28.6 \%)$ & $12(46.2 \%)$ & 0.218 \\
Pruritus & & & $0.041^{*}$ \\
Satisfaction score & $4.52 \pm 0.60$ & $4.15 \pm 0.80$ & 0.893 \\
Function & $3.67 \pm 1.11$ & $3.62 \pm 0.98$ & \\
Aesthetics & & & 0.427 \\
Scar quality & $6.10 \pm 1.58$ & $6.55 \pm 1.57$ & 0.391 \\
Total VSS score & $1.42 \pm 0.90$ & $1.71 \pm 0.90$ & 0.125 \\
Pigmentation & $1.12 \pm 0.59$ & $1.38 \pm 0.50$ & 0.450 \\
Vascularity & $1.67 \pm 0.58$ & $1.85 \pm 0.73$ & 0.182 \\
Pliability & $0.77 \pm 0.77$ & $1.05 \pm 0.67$ & \\
Height & & &
\end{tabular}

${ }^{*} \mathrm{P}<0.05$. FTSGs, full-thickness skin grafts; VSS, Vancouver Scar Scale. 